in 1936 , by 15 parts in $10^{6}$. 'The change is attributed to a possible variation during the past years in the inductance standard. The Light Division has been mainly occupied with the development of the new methods of producing and copying diffraction gratings suggested by Sir Thomas Merton. Flat gratings with a ruled area of $6 \mathrm{in}$. by $6 \mathrm{in}$. have been made, and a special lathe, which will enable larger gratings of particular value to astronomers to be produced, was being constructed.

In the Metallurgy Division, investigations on the influence of the interstitially dissolved elements, oxygen and carbon, on the properties of iron, the elastic and plastic deformation of metals, the creep of high-temperature metals and alloys, and the equilibrium diagrams of alloys of titanium and oxygen and of titanium, iron and oxygen, have proceeded successfully. The Ultrasonics Section of the Physics Division has been concerned with the measurement of the elastic constants of solids by dynamic methods and of the absorption of 'Perspex' and 'Catalin' over the range 1-3 Mc./s. The Radiology Section, in order to establish British absolute standards of various radioactive isotopes, has made intercomparisons of measurements and techniques of several organizations, including the Atomic Energy Research Establishment and the Royal Cancer Hospital. Agreement has been reached on some isotopes.

The bulk of the research carried out in the Radio Division has been on wave propagation, and much basic information has been obtained. The study of ionospheric conditions has continued. Semi-conductors have been given special attention, and noise in germanium diodes and triodes, together with an examination of factors affecting the performance of these valves as rectifiers, amplifiers and oscillators, have been the subjects of investigation. Finally, the report records that the volume of work submitted. for test in the Test House has increased appreciably, in some instances by as much as 50 per cent, and the sum received annually from test fees has been almost doubled.

1 See Nature, 168, 594 (1951).

2 "Rec. Devel. Tech. Main. Stand." (London: H.M.S.O.. 1952.)

${ }^{3}$ See Nature, 168, 410 (1951)

${ }^{4}$ See Nature, 169, 267 (1952).

\section{HUMAN RELATIONS IN INDUSTRY}

$\mathrm{T}$ HE scientific study of human relations in industry has been described by Dr. W. H. Scott, of the University of Liverpool, in two issues of the Journal of the Institute of Personnel Management (34, No. 319 ; March 1952 ; and 34, No. 321 ; September 1952).

In the first article Scott examines the nature and aims of the work of the industrial sociologist. The industrial sociologist, he suggests, studies the factory as a social system, as a network of relationships between individuals and groups. The most superficial analysis reveals that these relationships are far more complex than the traditional managementworker antithesis suggests. There are the relationships which exist between persons at various levels in the 'line' organization, from the top executive to the charge-hand; between executive and 'staff" personnel; between rank-and-file employees and their immediate supervisors; between managerial personnel and employee representatives; between rank-and-file employees and employee representatives ; and between the various persons at a similar level in the organization as, for example, the members of the 'top' management group, the departmental managers, the foremen, or the rank-and-file employees in a particular department.

Although the sociologist may single out one or more of these particular aspects of relationships for detailed study, all are interdependent to some extent. Thus the relationships between employees and their immediate superiors are influenced by the ralationships which exist at higher levels in the 'line', and the relationships between higher managerial personnel and employee representatives are determined to a large extent by relationships within the higher management group itself. It is the recognition of this interdependence which is leading sociologists increasingly to insist that any particular problem of relationships within an organization must be studied, and resolved, in terms of the totality of which it forms only a part. Endeavours to change the behaviour of supervisors by the development of more suitable selection and training procedures, for example, will be of limited value unless such endeavours are made as part of a wider plan to change attitudes and behaviour throughout the 'line' organization as a whole. Moreover, the factory does not exist in vacuo, and behaviour within its walls is closely associated with the attitudes and relationships which exist in the wider community.

After considering the difficulties confronting those who wish to investigate social relationships in industry, in his second article Scott discusses some of the contributions of current systematic studies by social scientists.

The common beliefs that efficiency and, concomitantly, productivity, necessarily arise out of individual employee satisfaction or high group morale are shown to lack validity. Social scientists are concerned to discover the conditions under which high productivity and high morale are most likely to co-exist, since under such conditions the satisfaction of the needs of both the individual and the organization will be at its greatest. Evidence is increasing that fuller opportunities for self-development and a greater measure of self-determination in industry are the basic pre-requisites. This does not imply the need for more and more joint consultation ; rather is it the day-to-day relationships on the job which are crucial in determining morale and attitudes. The pressing need is for the development of leadership ability and skills at all levels. Leadership at the supervisor-employee level should be integrative, seeking to elicit the maximum contribution from earch member of the work team by increasing opportunities for participation and self-development, and by ensuring that the feelings and ideas of all are brought to bear on problems and decisions.taken. This will not be achieved simply by developing elaborate schemes for the training of supervisors. Consultative leadership must become an accepted administrative practice at all levels.

The importance of a permissive or consultative, rather than an authoritarian, type of leadership in industry is emphasized by the differences between formal and informal social organization, which sociologists have clarified.

Formal organization defines the division of functions among persons or groups of persons and the relationships deemed necessary for their co-ordination. 
It nevor quite works in the manner prescribed, however, owing to the growth of informal relationships which eut across formal lines at all levels.

In some departments supervisors and even employees may approach their manager directly, while in others a rigid observance of the 'channels' may bo insisted upon ; foremen in different departments may often arrange matters between themselves without 'going through' their respective managers; staff specialists may achieve a position in which they are regarded as executives, although formally they may have a purely advisory status. Other informal relationships are only indirectly connected with the formal organization, such as the groups which arise among employees who work in close proximity to one another or cliques which have a political or religious basis. It would be erroneous to regard this informal organization as unstable or haphazard, for it usually follows a very definite and persistent pattern, and, like all stable relationships, develops characteristic values, norms, beliefs and attitudes which tend to become stereotyped, to be resistant to change, and to be binding on the members of the group. In a real sense, therefore, the informal organization is the one which matters.

In conclusion, Scott suggests that the more the formal and informal organization can be brought into harmony, the more likelihood there is of achieving a system of social relationships which will be effective both in satisfying individual needs and in attaining common goals.

T. H. HAWKINS

\section{JOURNAL OF EMBRYOLOGY AND EXPERIMENTAL MORPHOLOGY}

G

ROW'TH and change in the needs of scientific T publication can often be met by the expansion and alteration of existing learned periodicals, but circumstances may from time to time make the establishment of new journals desirable. In Europe, embryologists, and workers on problems of morphogenesis and developmental change in the adult, have felt the lack of a medium of publication that would both bring together closely related work at present scattered and facilitate the growth of a fruitful co-operation between the many different approaches to the central problems presented by developmental processes.

An attempt to meet this need is being made in the publication of a new quarterly, the Journal of Embryology and Experimental Morphology. In founding this journal the original sponsors, a group of British workers in collaboration with Profs. Sven Hörstadius (Uppsala), Chr. P. Raven (Utrecht) and M. W. Woerdeman (Amsterdam) have taken the opportunity of ensuring a fuller measure of international control of its scientific policy than is generally regarded as practicable. The editorial board, which has at present representation from Belgium, Finland, France, Great Britain, Holland, Italy, Sweden and Switzerland, will determine long-term scientific policy as well as giving the editor (M. Abercrombio) active support in carrying it out.

The editorial board met for the first time on January 3 at University College, London. British members were joined by Profs. A. M. Daleq (Brussels), A. Stefanelli (Rome) and E. C. Wolff (Strasbourg).

Reports from the chairman (Prof. J. Z. Young) and the editor showed that it would be possible to publish four parts in 1953 and that the first issue could be expected during the spring. As was to be expected of an inaugural meeting, a certain amount of discussion centred on problems of a technical and administrative nature; but perhaps the most important discussions were those in which the scientific policy and scope of the journal were defined. There was general agreement that studies on embryogonesis, on regeneration, on growth, and on developmental changes in the older organism as well as on tho physiology of fotal-maternal relations would all fall within the scope of the journal. Parts of other fields, notably sexual endocrinology, the cytology of gametogenesis, and developmental genetics, would, in their ontogenetic aspects, be served. On the other hand, studies in these subjects which were directed primarily to clinical ends, or were otherwise better published in existing journals, would not normally be taken.

Although English will be the usual language of articles in the journal, provision has been made for the acceptance of a number in French and German; and although articles will, for the most part, be reports of original resoarches, review articles of exceptional value may occasionally be accepted.

The editorial board will meet annually, and it is hoped that its future meetings will not only review the work of the journal but will also be the occasion of the interchange of scientific information. If this happens the journal may well come to serve its field of biology in two of the most important ways open to it: by providing a common public ground in its pages for research into developmental processes ; and by encouraging the intornational exchange of opinion and knowledge through the less formal means of discussions associated with editorial board meetings.

Members of the editorial board are sensible of their indebtedness to the outside bodies who have made the journal possible. In particular, the Company of Biologists, Ltd., which will publish it, and the Clarendon Press, which will produce it, have provided the basis for the whole project, while the British Council has helped to realize one of its most important features, namely, the participation of workers from many countries in the work of the editorial board meeting.

D. R. NEwTH

\section{VARIABILITY OF INTERNAL ENVIRONMENT AND THE MECHANISMS OF BIOLOGICAL CORRELATIONS}

\section{BY EUGENE SCHREIDER}

Laboratoire d'Anthropologie Physique, I rue René Panhard,
Paris $13 e$

$\mathrm{T}$ is generally accepted that internal environment 1 is practically constant. The theory of homeostasis reinforced this old belief, for in its original form it stressed the very narrow limits of biological variations. To-day we can read that in vertebrates even the blood pressure is constant. But variability can now be classified as 'narrow' or 'wide'; we can compare coefficionts of variation taken from different biological fields. If we find that they are significantly lower for physiological than for other characters, the relative fixity of internal environment should be 